\title{
VI \\ AGRONEGÓCIO, DESENVOLVIMENTO E SUSTENTABILIDADE: REFLEXÕES SOBRE A FORMAÇÃO DOS SUJEITOS NA AMAZÔNIA BRASILEIRA*
}

\author{
Gisele Silva Gomes \\ Luclécia Patrocínio de Jesus
}

\section{Introdução}

Desde o início da década de 1970, a floresta amazônica sofre com o desenvolvimento orquestrado por uma economia que beneficia o capital. A redução da floresta acontece de forma desenfreada com as derrubadas, queimadas e grilagens de terra em áreas de preservação ambiental e indígenas. Em 2020, este cenário não mudou nem houve diminuição. A não aplicação de multas por crimes ambientais e as retaliações as operações aos órgãos ambientais com o apoio do governo federal alavancam o ranking do desmatamento, incentivando ocupações irregulares de terras públicas com promessas de regularização.

O governo atual fortaleceu a impunidade com o decreto $\mathrm{n}^{\circ} 9.760$, que garante ao infrator audiência de conciliação, permite o parcelamento de multas e diminue ou, até, converta as penalidades com prestação de serviços de melhoria e recuperação da qualidade do meio ambiente.

Este capítulo discute problemas socioambientais relacionados ao agronegócio, desmatamento, grilagem e o êxodo rural na Amazônia. Pois, ao compreender a relevância e a necessidade de ampliação do debate desses temas, se torna necessário agir de forma intencional na resolução dos problemas e questionar sobre a formação dos sujeitos da região

\footnotetext{
*DOI - 10.29388/978-65-86678-45-1-0-f.139-152

${ }^{1}$ Mestranda em Educação, no Programa de Pós-Graduação em Educação - PPGE, da Universidade Federal do Oeste do Pará - Ufopa. Graduada em Pedagogia pela Ufopa. E-mail: giselegomes7@hotmail.com

${ }^{2}$ Mestranda em Educação, no Programa de Pós-Graduação em Educação - PPGE, da Universidade Federal do Oeste do Pará - Ufopa. Graduada em Pedagogia pela Ufopa. E-mail: luclecia_patrocinio@hotmail.com
} 
a fim de compreender a universidade contribui na reprodução das práticas que vão encurtar a temporalidade do ser humano na terra, ou ela visa à melhoria do ambiente para garantir a permanecia da humanidade no planeta?

O enfoque a partir da universidade foi defido ao considerar o papel formador da instituição, bem como sua relevância na produção do conhecimento, de pesquisas e na formação de profissionais que atuarão em diversos setores da sociedade.

\section{Conceitos necessários}

Para a discussão do problema proposto, três conceitos precisam ser destacados: Agronegócio; Desenvolvimento e Desenvolvimento Sustentável.

\section{Agronegócio}

O agronegócio ${ }^{3}$ se refere à soma das operações de produção e distribuição de suprimentos agrícolas, do armazenamento, processamento e distribuição dos produtos agrícolas e itens produzidos. Este encadeamento de ações interdependentes transforma o agronegócio unidade de análise, trazendo novas potencialidades e desafios ao desenvolvimento econômico harmônico e sustentado.

\section{Desenvolvimento}

O conceito de desenvolvimento é complexo e dialético, podendo ser considerado por pontos de vista diferentes, conforme a concepção teórica e epistemológica. Neste texto, foi optada a utilização do conceito explicdado por Oliveira (2002, p. 40), que diz:

\footnotetext{
${ }^{3}$ Definição:http://www.bdpa.cnptia.embrapa.br/consulta/busca? $\mathrm{b}=$ ad\&id $=495833 \&$ biblioteca $=$ vazio\&bua $=$ autoria: $\% 22$ RUFINO $\% 20$ J.L. $\% 20 \mathrm{dos} \% 20$ S. $\% 22 \& q F a c e t s=$ autoria: $\% 22$ RUFINO,$\% 20$ J.L. $\% 20$ dos $\% 20$ S. $\% 22 \&$ sort $=\&$ paginacao $=$ t\&pagina $\underline{\text { Atual }=1}$
} 
Desenvolvimento deve ser encarado como um processo complexo de mudanças e transformações de ordem econômica, política e, principalmente, humana e social. Desenvolvimento nada mais é que o crescimento - incrementos positivos no produto e na renda - transformado para satisfazer as mais diversificadas necessidades do ser humano, tais como: saúde, educação, habitação, transporte, alimentação, lazer, dentre outras.

Assim, considerando as necessidades humanas de uma região, de um país ou do próprio mundo, quando se pensa o desenvolvimento econômico e o lucro de poucos não deveria sobrepor-se as necessidades da vida em todas as suas dimensões.

\section{Desenvolvimento sustentável}

Segundo o Relatório Nosso futuro comum, desenvolvimento sustentável "é aquele que atende às necessidades do presente sem comprometer a capacidade de as gerações futuras atenderem as suas próprias necessidades" (CMAD, 1991, p. 46).

Quando se propõe esse tipo de modelo dedesenvolvimento, a reflexão que se estabelece se associa à necessidade de pensar na vida humana e impõe considerar condições - neste caso, materiais - de manutenção da vida.

\section{Problemas socioambientais enfrentados na região amazônica em seu processo de desenvolvimento}

A ocupação para o desenvolvimento da Amazônia se intensificou nas décadas finais do século XX, com o projeto de integração nacional. Nesse período, as perversidades tanto contra o meio ambiental e como questões sociais marcavam a floresta com suor, lágrimas e sangue para que houvesse "desenvolvimento econômico".

Nas décadas de 1960 e 1970, no governo Médici, iniciou o plano de integração da Amazônia à economia nacional, oferecendo-se, por meio da Sudam, incentivos fiscais, principalmente para pecuária, e milha- 
res de fazendeiros chegam à região. O slogan da época era: "ocupar terras sem homens por homens sem-terra”. Segundo os noticiários, o presidente visitou e sobrevoou a região do nordeste, principalmente nas áreas castigadas pela seca. Sua ida ao nordeste resultou em ações de ocupação da floresta Amazônica

Assim, a terra que "jorrava leite e mel" foi ocupada por imigrantes, em sua quase totalidade, nordestinos pobres, que chegavam com a ilusão de ter registro de trabalho e um pedaço de chão para plantar e trazer o restante da família. Porém, muitos se depararam com trabalho pesado (derrubada da floresta), em condições precárias de sobrevivência, sendo obrigados a pagar pelas ferramentas (bota, foice, enxada, machado, tesado). Os fomentos do governo eram repassados ao grande fazendeiro e, ao pobre, restava o trabalho insalubre, análogo à escravidão.

Não havia preocupação ambiental ou social nas aberturas de estradas no meio da floresta. As mais de 29 etnias indígenas atingidas com "progresso" não foram consultadas ou ouvidas sobre o impacto que traria a obra faraônica, conhecida hoje como Transamazônica.

A união alegava desconhecer a existência de moradores, os índios Araras tiveram parte de suas terras transferidas para uma empresa privada e quando recorreram à justiça tiveram suas terras de volta, apesar da devolução, a estrada atravessou as suas terras, separando aldeias e fragmentando a área (LOUREIRO, 2009).

Conforme Loureiro (2009), a Amazônia do século XX foi como uma das principais exportadoras de produtos extrativos, in natura. Nesse período, as políticas dos governos militares promoviam quatro atividades econômicas na região: extração de madeira, pecuária, pesca industrial e mineração. Num primeiro momento (1970/1985), predominou a extração de madeira, pecuária e a pesca industrial; em seguida (1986/2000) com repercussão até os dias atuais, impuseram-se a mineração, "moderna pecuária" e a produção de grãos; eram produtos que apresentavam boas chances de aceitação no mercado externo, segundo análises econômicas da época, as quais, entretanto, não levavam em conta os efeitos negativos das atividades, implicando a exclusão social pela desestruturação da base produtiva em que se apoiavam as atividades tradicionais. 
Devido aos incentivos ficais e o sonho do desenvolvimento, a Amazônia Legal sofreu e segue sofrendo com a destruição da floresta nativa, atingindo o ecossistema e gerando impactos socioambientais.

O desmatamento vem de antes da grilagem e criação de pasto; seu inicio vem da ocupação de determinada área (terras públicas: reservas ambientais, indígenas e áreas destinadas à reforma agrária) pelo desmatamento, retirando-se árvores com altos valores comerciais de forma predatória, com utilização da mão-de-obra barata, é vendida ilegalmente, a madeira gerava recursos para a continuidade da devastação, utilizando maquinário e fogo. Após a retirada da floresta, para conformar a ocupação, planta-se capim e colocam-se algumas cabeças de gado, dando a entender que a terra é produtiva; por fim, regulariza-se a área desmatada ilegalmente, com o cadastro ambiental rural e do programa de regularização fundiária. O objetivo é gerar documentos de fachada para mostrar um histórico de ocupação e facilitar a posse definitiva.

Uma vez que a grilagem consolida, terras são vendidas e destinadas à pecuária. A legislação federal e as estaduais são, desde 2009, mais flexíveis ao grileiro. (Torres, 2020)

Com isso, a pecuária é a atividade econômica que mais desmata. $\mathrm{O}$ aumento das queimadas e o desflorestamento correspondem a $200 \mathrm{mi}$ lhões de toneladas anuais de dióxido de carbono, contabilizando $74 \%$ das emissões de gases, aumentando o efeito estufa e causando mudanças climáticas. Pesquisas indicam que o desmatamento pode mudar o regime de chuvas do país - por ironia, prejudicando o próprio agronegócio.

Até 2017, devastaram-se 20\% da Amazônia brasileira, sendo que 2/3 dessaa área transformou-se em pasto. Segundo o documentário "Sob a pata do boi”, o estado do Pará era maior produtor de carne bovina país.

O relatório da associação brasileira das indústrias exportadoras de carne - ABIEC (2018) indica que o município com o maior rebanho bovino do país continua sendo São Félix do Xingu (PA), com quase 2,5 milhões de cabeças de gado; nos últimos 20 anos, o rebanho desse município cresceu mais de $800 \%$. 
Quadro 1: Os dez municípios com maior rebanho de gado do Brasil.

\begin{tabular}{|l|c|c|c|}
\hline Município/Estado & $\begin{array}{c}\text { Rebanho } \\
\text { em 1998 } \\
\text { (cabeças) }\end{array}$ & $\begin{array}{c}\text { Rebanho } \\
\text { em 2008 } \\
\text { (cabeças) }\end{array}$ & $\begin{array}{c}\text { Rebanho } \\
\text { em 2018 } \\
\text { (cabeças) }\end{array}$ \\
\hline São Felix do Xingu - PA & 242.703 & 1.812 .870 & 2.238 .262 \\
\hline Corumbá - MS & 1.557 .650 & 1.935 .896 & 1.885 .751 \\
\hline Ribas do rio Pardo - MS & 1.029 .95 & 1.176 .151 & 1.144 .805 \\
\hline Cáceres - MT & 552.359 & 823.804 & 1.072 .461 \\
\hline Marabá - PA & 192.000 & 478.100 & 1.024 .102 \\
\hline Vila Bela da Santíssima Trindade - & 380.000 & 803.594 & 979.374 \\
MT & & & \\
\hline Porto Velho - RO & 132.990 & 608.664 & 968.778 \\
\hline Juara - MT & 560.494 & 905.470 & 951.445 \\
\hline Novo Repartimento - PA & 142.200 & 381.628 & 899.103 \\
\hline Cumaru & 101.590 & 440.378 & 845.651 \\
\hline
\end{tabular}

Fonte: Athenagro, IBG, 2018.

O monitoramento anual feito pelo instituto nacional de pesquisa especiais-INPE (2019) aponta a rapidez com que a floresta foi destruída em 2019 no município de São Félix do Xingu (PA). A destrição do equivalente a um terço do desmatamento na Amazônia ocorreu, em grande parte, na área de preservação ambiental Triunfo do Xingu.

Os danos ambientais provocados em poucas dezenas de anos pela pecuária principalmente, mas também por outras atividades, são bem visíveis pelos habitantes: queimadas em nascentes e margens de rios, desertificação em determinadas áreas, empobrecimento ecológico, assoreamento e perda de perenidade de determinados rios e outros. (LOUREIRO, 2009, p.58).

Outra atividade bem desempenhada na região amazônica é a sojicultura. Segundo estudo da Embrapa (2016), a soja chegou ao Brasil por volta de 1882, vinda dos Estados Unidos. A partir de 1900, iniciou-se o plantio do grão no Rio Grande do Sul, com bom desenvolvimento da produção em função das condições climáticas. Devido à demanda internacional pela compra dos grãos, a soja começou a ser produzido em escala cada vez maior no Brasil, fazendo do país o segundo produtor mundial de soja. 
A expansão da soja no território amazônico se deu a partir do melhoramento genético do grão e pela migração de agricultores provenientes do centro-sul brasileiro a partir da década de 1990. A alavancada da produção em cidades do Pará ocorreu com a chegada de obras como as do porto da Cargill em Santarém - PA, contribuindo para o escoamento da produção do estado do Mato Grosso.

O crescimento da produção de soja na região decorreu com a instalação do terminal da Cargill, terras baratas, atraindo produtores rurais de outras regiões. O avanço da soja na região ocasionou diversos conflitos sociais relacionados à exclusão dos modos de vida que tem tendo por base a agricultura familiar. São comuns relatos casas queimadas, expulsão de famílias, ameaças de morte, intimidações às lideranças locais, grilagem de terras e a supressão de florestas - fatos que se tornaram manchetes dentro e fora do Brasil (OSORIO, 2018).

Em 2008, a Comissão Pastoral da Terra (CPT) apresentou relatório detalhado sobre a situação vivida por comunidades afetadas pelo plantio da soja:

Uma situação danosa às famílias de camponeses é o período de aplicação de produtos químicos nos plantios de soja. Como os campos de soja estão localizados próximos às comunidades, o vento carrega facilmente os produtos químicos para dentro das casas, causando mal - estar às pessoas. Os moradores relatam que quem mais sofre neste processo são as crianças. Citam, inclusive, que as aulas foram paralisadas nos dias de aplicação dos produtos químicos. Essa situação é alarmante à medida que as populações locais são ignoradas e expulsas direta ou indiretamente para dar lugar aos campos de soja. Escolas e igrejas estão sendo fechadas, por não haver mais comunitários. Quem resiste em permanecer é obrigado a conviver com as regras impostas pelos novos donos da terra. (CPT, 2008, p. 7).

De acordo com Osório (2018, p.55) conforme citado por Domingues e Bermann (2012), o cultivo da soja na região trouxe, ademais dos impactos sociais e ambientais, o falso desenvolvimento, com baixa geração de empregos, pois a cultura da soja emprega pouca mão-de-obra 
por hectare, de modo que as comunidades locais não se beneficiam da implantação e do avanço da soja.

Domingues e Bermann (2012, p.9) apontam outro fator impactante negativamente na organização social da região: o deslocamento de populações para as cidades, devido à introdução da monocultura e estabelecimento de grandes propriedades rurais. Todos esses fatores acabam interferindo negativamente na produção de alimentos tradicionais e gerando aumento do desemprego, comprometendo a segurança alimentar da população local.

A história de ocupação e exploração econômica da Amazônia nos ensina que esses modelos de desenvolvimento não trouxeram empregos ou geração de renda, conflitam com a realidade cultural e deterioram os recursos naturais da região.

Medeiros e Pantoja (2015) entendem que é possível avançar um modelo de desenvolvimento que promova uma Amazônia saudável e sustentável com base na governança social e territorial, desenvolvimento e efetivação de produção sustentável e conservação e valorização do capital natural. Para os autores, é necessário o fortalecimento da economia florestal como atividade econômica que contribua com a redução e o controle do desmatamento e da pobreza.

\section{A necessidade de formação dos sujeitos para o desenvol- vimento sustentável}

Pensar a formação de um sujeito que reflete sobre a história objetiva e o mundo em que vive, e seja apto a lutar por uma mudança nas políticas sociais e ambientais para o desenvolvimento sustentável da região amazônica é um caminho complexo e permeado por desafios.

Ao considerar o histórico de povoamento da região, a exploração indiscriminada dos recursos, o modelo de exploração das grandes corporações, do agronegócio e dos governos nas diversas esferas, se torna necessário uma formação crítica às condições postas para a região, que não priorizam o desenvolvimento humano em sua totalidade. 
Para tanto, a pergunta a fazer é: A universidade contribui na reprodução das práticas que vão encurtar a temporalidade do ser humano na terra, ou ela visa à melhoria do ambiente para garantir a permanecia da humanidade no planeta?

Considerar a formação dos profissionais que atuarão na região amazônica impõe pensar e desenvolver ações de sustentabilidade, objetivando não o lucro desenfreado em detrimento da natureza, mas a ampliação e manutenção de uma cultura que valorize o homem do campo, que respeite as comunidades, os povos tradicionais e que possibilite que as futuras gerações residentes na região amazônica usufruam de toda a riqueza e diversidade existente. E, mesmo que existam sujeitos particulares que compõe a complexidade da região, o seu interesse não deve ser sobreposto ao interesse coletivo que busca o bem comum. A saber:

Todos e cada um dos seres humanos que existiram até hoje se expressam fundamentalmente por uma tripla dimensão: são uma individualidade (Maria, José, João, Antônio); são seres da natureza (animal) - dependem de ar, água, contida, ferro, cálcio, vitaminas, sais etc. e, produzem as especificidades desta sua individualidade e natureza em relação com os demais seres humanos. (FRIGOTTO, 2001, p. 73).

Vale ressaltar que a sociedade de hoje, permeada por contradições e desenvolvida a partir de discriminação, exploração (ambiental e do humano) e desigualdades acentua disputas por terras e acelara a dimensão dos impactos ambientas já experimentados na região, como por exemplo, a monocultura no plantil que se insere como parte do modelo de 'desenvolvimento' implantado na região que gera impacto devido à contaminação das águas e do solo.

As reformas neoliberais, cujo escopo é de liberar o capital à sua natureza violenta e destrutiva, abortam as imensas possibilidades do avanço científico de qualificar a vida humana em todas as suas dimensões, inclusive diminuído exponencialmente o tempo de trabalho necessário à reprodução da vida biológica e social e dilatan- 
do o tempo livre - tempo de liberdade, fruição, gozo. (FRIGOTTO 2001, p. 72).

Nesta lógica, além dos problemas enfrentados ao longo da vida, os sujeitos precisam das demandas do mercado. Esse problema, em grande medida, influi no processo de formação dos indivíduos e como se apresentarão frente às demandas de sobrevivência objetiva. Daí emerge concepções que buscam o sujeito flexível, com competências e habilidades para suprir exclusivamente a demanda do capital naquela localidade.

Sirva de exemplo a criação do curso de Engenharia de Minas, pela Universidade Federal do Oeste do Pará - Ufopa, campus de Juruti PA. Em certa medida é um curso estratégico considerando-se o potencial de exploração de minérios do município; no entanto, há que interpelar se sua criação fortalece as demandas do capital ou visa formar um sujeito consciente dos impactos, disposto a agir de forma sustentável.

Discutindo as questões de contradição entre a universidade, à ciência e a sociedade, Goergen (1998, p. 6), afirma ser

Urgente superar este "abreviamento" do papel da universidade que reduziu sua função a formar indivíduos para atender "necessidades sociais", sejam elas quais forem e recuperar seu papel de instância crítica da sociedade a partir de interesses humanos mais amplos democraticamente discutidos.

Há um grande problema quando se pensa a formação aparelhada e fundada para atender a ordem econômica, pois o que ocorre é que as relações de trabalho no capital se realizam de forma alienada, privando o sujeito do pleno desenvolvimento e do controle das forças produtivas, pois, "quando o capital apropria-se da mais-valia, trata-se de uma apropriação que aliena os trabalhadores do produto de seu trabalho, portanto, uma apropriação alienante”. (DUARTE, 2001, p. 164)

Assim, a formação profissional necessita estar vinculada com a consciência da realidade, almejando uma dinâmica em que os sujeitos se apropriem dos processos e de suas implicações, de modo que a relação de alienação seja (parcialmente) superada e o estudante e o profissional exerçam sua atividade com crítica, visando à melhoria do desenvolvi- 
mento humano e o bem-estar coletivo, independentemente da área do conhecimento que atua ou atuará. - Pensar a superação total da alienação considerando o modelo econômico atual além de complexo é também um processo dialético devido à estrutura de contradição e desigualdade existente -

A formação para agir de forma sustentável não deve advir de uma única área, sendo necessário que todos os sujeitos, principalmente aqueles fromados por instituições públicas, saibam agir de acordo com demandas socioambientais. E esse processo exige ação coletiva de professores, pesquisadores e estudantes que estejam dispostos a atuar na produção científica e na sociedade, representando as causas na perspectiva de um desenvolvimento sustentável para a Amazônia.

Há que investir em garantias para que os processos de formação ocorram e se desenvolvam na sociedade. Neste caminho, um passo importante foi iniciado quando o ${ }^{4}$ Programa de Interiorização da Universidade pública pelo país foi instituído, durante o governo do ex-presidente, Luiz Inácio Lula da Silva. Neste sentido, como apontam Colares, et al. (2017, p. 281)

[...] não basta oferecer cursos de graduação e pós-graduação no interior da Amazônia, segundo o modelo da capital, mas apresentar uma proposta formativa diferenciada com o propósito de respeitar as culturas locais, preparando os indivíduos para atuarem competentemente nessas comunidades, para que eles as reinterpretem no contexto da cultura geral e global e assim possam melhor reescrevê-las.

Evidenciando os critérios pertinetes a essa reescrita proposta a partir do modelo de desenvolvimento adotado para a Amazônia brasileira, superando a exploração, o desmatamento, as queimadas e a grilagem de terra.

É importante que passos sejam dados para que a mudança nos paradigmas socioambiental ocorra, pois, como adverte Saviani (2012, p.

\footnotetext{
${ }^{4}$ Durante a implementação deste programa pelo Brasil, no estado do Pará, além das instituições de ensino superior existente, foram criadas outras duas universidades, a Universidade Federal do Oeste do Pará - Ufopa, e a Universidade Federal do Sul e Sudeste do Pará - UNIFESSPA.
} 
73), "a educação [...] não transforma de modo direto e imediato e sim de modo indireto e mediato, isto é, agindo sobre os sujeitos da prática".

Considerando a representação da universidade frente à sociedade, é imprescindível ela assuma seu compromisso com a história e com a identidade da localidade em que está inserida, realizando interseção entre as práticas sociais e a necessidade de um desenvolvimento que pense a subsistência futura da humanidade em todos os aspectos.

\section{Considerações finais}

Ao longo deste texto foram apresentados e debatidos alguns problemas socioambientais enfrentados na região amazônica, ressaltando a necessidade de formação de sujeitos que considerem esta problemática e saibam se posicionar frente a ela.

Pois, o avanço do desmatamento, do êxodo rural, da monocultura da soja, o uso incondicionado de agrotóxicos e de tantos outros problemas que avançam sobre a floresta - especificamente na região Oeste do Pará - precisa ser enfrentado urgentemente, pois os índices de degradação ambiental interferem no círculo natural da vida, com impacto perverso na geração atual e nas futuras.

A questão socioambiental na região precisa ser debatida em pesquisas, aulas, seminários, não se restringindo a cursos de graduação ou pós-graduação que abordam especificamente esta temática. A saber, é imprescindível que a reflexão perpasse a formação de todos os estudantes para que o tema reverbere na sociedade civil, visando ao aumento da conscientização ambiental.

Reverberar tais ideais a partir da universidade implica reconhecer o lugar dessa instituição no desenvolvimento humano, nos processos de produção, criação de conhecimento e tecnologias que influênciam a vida dos sujeitos particulares e a sociedade.

Talvez seja complexo efetivar essas questões enquanto o atual sistema que provoca a exploração e o desequilibrio social existir. No entanto, passos precisam ser dados no caminho da mudança.

Defender uma formação humana livre e universal do ser humano (Duarte, 2001) que pensa pelo bom desenvolvimento e luta por condi- 
ções dignas de vida é neste ponto, um dos ideais para o estabelecimento de uma prática reflexiva e consciente do desenvolvimento com sustentabilidade.

\section{Referências}

COLARES, Anselmo Alencar; FERREIRA; Maria Antonia Vidal; COLARES, Maria Lília Imbiriba Sousa. Ensino superior na Amazônia: cooperação interinstitucional e a formação de uma escola de pensamento. Revista Práxis Educacional, Vitória da Conquista, v. 13, n. 25, p. 273-290, maio/ago. 2017.

DOMINGUES, Mariana Soares; BERMANN, Célio. O arco de desflorestamento na Amazônia: da pecuária à soja. Ambiente e Sociedade, v. XV, n. 2, p. 1-22. 2012.

DUARTE, Newton. Vigotski e o “Aprender a Aprender": Crítica às Apropriações Neoliberais e Pós- Modernas da Teoria Vigotskiana. Campinas - SP: Editora autores associados, 2001.

COMISSÃO MUNDIAL SOBRE MEIO AMBIENTE E

DESENVOLVIMENTO. Nosso futuro comum. 2. ed. Rio de Janeiro: Editora da FGV, 1991.

COMPRE RURAL. Top 10 municípios com maiores rebanhos de gado do Brasil. Compre Rural. 16 de abril de 2019. Disponível: <https://www.comprerural.com/top-10-municipios-com-maiores-rebanhos-de-gado-do-brasil/>. Acessado em: Junho de 2020.

EMBRAPA. Empresa Brasileira de Pesquisa Agropecuária. Soja. 2016. Disponível em: <https://www.embrapa.br/soja/cultivos/soja1>. Acessado em: Junho de 2020.

FRIGOTTO, Gaudêncio. Educação e trabalho: bases para debater a Educação Profissional Emancipadora. PERSPECTIVA, Florianópolis, v.19, n.1, p.71-87, jan./jun. 2001.

GOERGEN, Pedro. Ciência, sociedade e universidade. Educação \& Sociedade, v. 19, n. 63, ago. 1998.

LOUREIRO, Violeta Refkalesfsky. A Amazônia no século XXI: Novas formas de desenvolvimento. São Paulo: Empório do livro, 2009. 
OSORIO, Raissa Macedo Lacerda. A produção de soja no Oeste do Pará: a tomada de decisão do produtor rural e as características da atividade produtiva em meio à floresta amazônica. Tese de Doutorado. Brasília, 2018. MEDEIROS, Rodrigo; PANTOJA, Eugênio. A história da exploração da floresta foi cheia de erros. Mas ainda dá tempo mudar e criar um futuro para se orgulhar. Época. 01 de nov. de 2016. Disponível: < https://epoca.globo.com/ colunas-e-blogs/blog-do- planeta/amazonia/noticia/2015/06/o-desafio-dodesenvolvimento-sustentavel-na- amazonia.html>. Acessado em: Junho de 2020 .

OLIVEIRA, Gilson Batista de. Uma discussão sobre o conceito de desenvolvimento. Revista FAE, Curitiba, v. 5, n. 2, p. 37-48, maio/ago. 2002. Disponível em: <https://revistafae.fae.edu/revistafae/article/view/477>. Acessado em: maio de 2020 .

SAVIANI, Demerval. Escola e democracia. 42. ed. Campinas, SP: Autores Associados, 2012. 5 v. (Coleção Polêmicas do Nosso Tempo).

Sob a pata do boi. Direção: Marcio Isensee e Sá. Produção: Associação o Eco. Documentários Imazon, 2018. Disponível em: <https://www.videocamp.com/pt/movies/sob-a-pata-do-boi $>$. Acessado em: 18 jun.2020. 